\title{
O SABER FAZER ENOGASTRONÔMICO DO TERRITORIO DO VALE DOS VINHEDOS/RS.
}

\author{
The enogastronomy know how in "Vale dos Vinhedos" territory / RS
}

\author{
Roberto do Nascimento e Silva \\ Universidade de Santa Cruz do Sul - UNISC - Santa Cruz do Sul - Rio Grande do Sul - Brasil
}

\author{
Mônica Pons
}

Universidade de Santa Maria - UFSM - Santa Maria - Rio Grande do Sul - Brasil

Vander Valduga

Universidade Federal do Paraná - UFPR - Curitiba - Paraná - Brasil

\begin{abstract}
Resumo: Atualmente, diversos territórios buscam expressar seus hábitos, sua cultura e seu modo de vida através de produtos ou processos que as particularizam frente às demais, proporcionando aos visitantes e visitados, sensações de exclusividade a partir de experiências vividas nestes locais. A enogastronomia tem recebido, além de valorização regional, status de tema de pesquisas científicas ao longo dos últimos anos. Todavia, estudos relacionados aos seus saberes fazeres têm recebido pouca atenção, enquanto tema de estudos acadêmicos no país. Entende-se por enogastronomia a união de segmentos sustentada por um tripé que compreende o produtor rural, as empresas (vinícolas e restaurantes) e o território, onde são desenvolvidos e aplicados conhecimentos teóricos, técnicos e práticos no oferecimento de produtos particulares e de qualidade aos consumidores finais. Este artigo tem por objetivo realizar uma reflexão sobre o saber fazer enogastronômico do território do Vale dos Vinhedos/RS. O marco teórico foi referenciado no materialismo histórico dialético e no estudo de caso. Como método de levantamento dos dados, se buscou analisar as entrevistas utilizadas para o desenvolvimento da pesquisa doutoral no ano de 2013. O procedimento de interpretação dos dados está referenciado na análise de conteúdo e os resultados evidenciam o saber fazer enogastronômico do território do Vale dos Vinhedos.
\end{abstract}

Palavras-chave: Território. Saber fazer. Enogastronomia. Vale dos Vinhedos

Abstract: Currently, several territories seek to express their habits, their culture and their way of life through products or processes that particularize against the other, providing to the visitors and visited, exclusive sensations from experiences in these places. The enogastronomy has been, besides regional appreciation, theme status of scientific research over the past few years. However, studies related to their doings knowledge have received little attention as a subject of academic studies in the country. It is understood by enogastronomia the union of segments supported by a tripod comprising the farmer, companies (wineries and restaurants) and the territory where they are developed and applied theoretical knowledge, technical and practical in providing private and quality products to final consumers. This article aims to carry out a reflection on the know-how enogastronomic the territory of the Valley of the Vineyards / RS. The theoretical framework was referenced in dialectical and historical materialism in the case study. As the data collection method, it sought to analyze the interviews used for the development of doctoral research in 2013. The interpretation procedure data is referenced in the content analysis and the results show the knowhow enogastronomic the territory of the Valley of the Vineyards.

Keywords: Territory, know how, Enogastronomy, "Vale dos Vinhedos" Valley. 


\section{Introdução}

Atualmente, diversas regiões buscam expressar seus hábitos, sua cultura e seu modo de vida através de produtos ou processos que as particularizam frente às demais, proporcionando aos visitantes e visitados, sensações de exclusividade a partir de experiências vividas nessas regiões. Exemplos desta diversidade podem ser observadas em localidades que têm o turismo, a gastronomia e a enologia como base da economia regional.

No caso da enogastronomia, a mesma está assumindo grande destaque em diversos âmbitos regionais pois, além de poder representar a forma de ser de uma sociedade, contribui economicamente para o desenvolvimento dessa, seja através da geração de emprego e renda, da interação com outros segmentos da economia, ou pela produção de alimentos diversificadas em pequenas propriedades rurais.

Desta forma, a enogastronomia tem recebido, além de valorização regional, status de tema de pesquisas científicas ao longo dos últimos anos. Isto se deve também ao crescente destaque que os hábitos culturais e costumes relacionados à enoalimentação vêm adquirindo, na medida em que traduzem e expressam experiências únicas e particulares de sociedades em diversos territórios mundo afora.

No caso da enogastronomia do Vale dos Vinhedos, tema deste artigo, as particularidades e o saber fazer de seu terroir chamam a atenção de visitantes das mais distintas regiões, que vão à serra gaúcha para degustar e saborear os produtos regionais, conhecer o artesanato local, hospedar-se na hotelaria, desfrutar dos vinhedos e parreirais, desenvolver atividades de enoturismo, além de conhecer o estilo de vida peculiar de seus moradores. O que torna este território, referência turística no Estado do Rio Grande do Sul, Brasil.

Nesse contexto, o artigo busca apresentar reflexões referentes ao saber fazer enogastronômico percebido no território do Vale dos Vinhedos, bem como suas interfaces com o desenvolvimento territorial.

Tendo como objetivo analisar o saber fazer enogastronômico do território do Vale dos Vinhedos/RS, procurou-se também conhecer a formação territorial da região, o que contribui para a construção do saber numa área que tem sua ênfase no "saber fazer", e que, por isso mesmo, é carente de trabalhos científicos, voltados à contextualização e à análise sistemática de temas relevantes na área.

O marco teórico desta investigação está referenciado no materialismo histórico dialético. Martins (2006, p.2) entende o materialismo histórico como possibilidade teórica, isto é, como instrumento lógico de interpretação da realidade, que contém em sua essencialidade a lógica dialética e neste sentido, aponta um caminho epistemológico para a referida interpretação.

Assim, na perspectiva do materialismo histórico a realidade é um processo histórico, dinâmico, provisório e em constante transformação.

Segundo Marx (1982), na produção social da própria vida, os homens contraem relações determinadas, necessárias e independentes de sua vontade, relações de produção estas, que correspondem a uma etapa determinada de desenvolvimento das suas forças produtivas materiais.

Neste sentido, percebe-se que a dialética torna-se necessária para a compreensão de um jogo marcado pelas contradições e tencionado pelas forças globais ao mesmo tempo em que sofre reações em escalas regionais.

Apesar da força da globalização, as regiões podem definir e redefinir sim, através das formas herdadas, tanto sociais e culturais quanto financeiras, os mecanismos de atuação no mercado regional, nacional e global.

Exemplos característicos de atuação regional no mercado global podem ser vistos na área da enogastronomia, em que as produções regionais caracterizam regiões e territórios através das particularidades de seus produtos e/ou do modo de vida de suas sociedades. 
No Brasil, citam-se exemplos de regiões que alcançaram destaque nacional e internacional através de produtos oriundos do setor enogastronômico, dentre eles, a região do Vale dos Vinhedos no Rio Grande do Sul, que através da Enogastronomia, reage frente aos monopólios do setor, oriundos da globalização. Os vinhos e derivados desta região, conforme a Associação de Produtores de Vinhos Finos do Vale - APROVALE (2012) possuem características organolépticas próprias, que são a expressão dos fatores naturais e dos fatores humanos na produção da uva, na elaboração e no envelhecimento do vinho.

Para a compreensão do território estudado, foi necessário utilizar como estratégia de pesquisa o estudo de caso através do qual, André (2005) salienta que pode-se gerar um conhecimento mais contextualizado, mais voltado para a interpretação e baseado em populações de referência, determinadas pelo pesquisador.

De acordo com Triviños (1987), o estudo de caso se caracteriza como estudo que parte de alguns pressupostos teóricos iniciais, mas procura manter-se constantemente atento a novos elementos emergentes e importantes para discutir a problemática em questão.

Para tanto, utilizou-se também as observações in loco no território do Vale dos Vinhedos, realizadas durante o período de agosto a dezembro de 2013 com o intuito de se conhecer a importância da enogastronomia para a formação da identidade territorial do Vale dos Vinhedos.

Além desta introdução, o segundo capítulo apresenta a linha etimológica do território, destacando elementos que elucidam a dinâmica territorial. No terceiro capítulo, se dá destaque à região do Vale dos Vinhedos, bem como sua caracterização e no quarto capítulo se aborda o saber fazer enogastronômico, apresentando as reflexões a partir dos resultados obtidos e, por fim, as considerações finais.

\section{TERRITÓRIO E DESENVOLVIMENTO}

O significado de território vem recebendo atenção de especialistas de diversas áreas do saber, destacadamente de geógrafos, sociólogos e economistas.

No intuito de aprofundar essa reflexão, faz-se necessário realizar, uma discussão referente aos conceitos e pressupostos que referenciam o tema proposto deste artigo. Nesta direção, percebe-se que a compreensão sobre o território auxilia no entendimento referente ao saber fazer enogastronômico do Vale dos Vinhedos.

Para Raffestin (1993), o território, é um espaço onde se projetou um trabalho, seja energia e informação, e que, por consequência, revela relações marcadas pelo poder onde os atores sociais ao se apropriarem concreta ou abstratamente de porções do espaço, delimitam territórios, mesmo que seja através de representações. Ao se produzir um valor, uma representação, um controle sobre o espaço, os homens erigem territórios que se articulam num campo relacional de poder.

Neste sentido, o autor apresenta a definição de território como complexa e densa, especialmente pela relação entre espaço e território.

Assim, faz-se necessário, para Raffestin, enfatizar uma categoria essencial à compreensão do território, que é o poder exercido por pessoas ou grupos sem o qual não se define o território. Em outras palavras, poder e território devem ser relacionados conjuntamente para que o conceito de território se consolide.

Para o autor, as relações de poder são multidimensionais e exercidas em todas as escalas, dentro e fora do território, onde, o poder é a chave de todas as relações. O poder não é possuído nem adquirido, mas simplesmente exercido (RAFFESTIN, 1993, p.7).

Pode-se dizer então que o conceito de território se associa ao espaço definido e delimitado por e a partir de relações de poder que não são restritas somente ao Estado, mas sim a todos os indivíduos. 
Nesta direção, Andrade (1995), destaca que o conceito de território não deve ser confundido com o de espaço ou de lugar, pois este é ligado à ideia de domínio ou de gestão de uma determinada área (ANDRADE, 1995, p.19).

Neste sentido, percebe-se que no território se constrói uma trama de relações complementares e conflitantes complexa entre o todo e a sociedade.

Santos (2000), salienta que o território se configura no espaço onde todas as ações humanas acontecem, sejam elas de reprodução material ou simbólica. É o lugar onde desembocam todos os poderes, todas as forças e todas as fraquezas, isto é, onde a história humana se desenvolve, a partir das manifestações de sua existência.

Nesta forma, Abramovay (1998) afirma que um território representa uma trama de relações com raízes históricas, configurações políticas e identidades que desempenham um papel ainda pouco conhecido no próprio desenvolvimento econômico.

Santos (2000), afirma que o território é tanto o resultado do processo histórico quanto a base material e social das novas ações humanas.

Daí o vigor do conceito, isto é, do convite a pensar processualmente as relações estabelecidas entre as dimensões do regional e do global.

Para o autor, o território surge como resultado de uma ação social que, de forma concreta e abstrata, se apropria de um espaço (tanto física como simbolicamente), por isso entendido como um processo de construção social.

Neste sentido pode-se afirmar que o conceito de território é mais amplo, complexo e abrangente em relação a diferentes fatores que compõe o desenvolvimento de regiões.

Pecqueur (2000) afirma que o desafio do desenvolvimento territorial consiste em evidenciar uma dinâmica que valorize a eficácia das relações não exclusivamente mercantis entre os homens para valorizar as riquezas das quais dispõem. Para o autor, o desenvolvimento territorial se caracteriza a partir da constituição de uma entidade produtiva enraizada num espaço geográfico.
O desenvolvimento territorial constitui um modelo de desenvolvimento dotado de características bem precisas que lhe são próprias e que se apoiam, essencialmente, na dinâmica de "especificação" dos recursos por um conjunto de atores constituído em “território". (PECQUEUR, 2005, p. 56)

De acordo com o autor, pode-se definir o desenvolvimento territorial como o processo de mobilização dos atores que leve à elaboração de uma estratégia com base em uma identificação coletiva com a cultura e o território.

Pecqueur (2009) destaca que o mecanismo de territorialização tem, como base, o princípio de especificação dos ativos, isto é, a busca pelos recursos próprios do território que permitirão a este se diferenciar dos demais territórios.

Desta forma, é válido destacar que o desenvolvimento de um território não pode ser implantado por decreto, ele resulta de uma dinâmica social particular, estimulada e mobilizada pelos atores regionais ao longo do tempo.

\section{A ENOGASTRONOMIA}

A enogastronomia tem papel de destaque em algumas experiências de desenvolvimento territorial. Através dela, as regiões e as sociedades criam suas identidades, fortalecem seus hábitos e costumes, resgatam suas crenças, preservam seu folclore, além de transmitirem tais valores para as futuras gerações.

Nesta perspectiva, a enogastronomia torna-se significativa para o território, por estar impregnada de cultura, identidade e de um modo particular de agir.

Através da enogastronomia é possível identificar costumes e tradições que não se revelam de forma palpável, ligados ao imaginário de cada pessoa, no despertar dos sentidos (visão, audição, paladar, tato e olfato), no expressar das diferenças, das semelhanças, das crenças e do sentimento de pertencimento, pois está cheia de marcas culturais e expressões sociais.

Pecqueur (2009) cita a qualificação do produto como estratégia de mercado, pois o valor agregado ao produto regional o torna único e exclusivo. Neste 
caso, sua valorização se dá pela diferenciação (na forma de produção e vinculação territorial), independentemente de preço ou custo de produção, diferenciando-o assim dos demais produtos oferecidos pelo processo global.

O autor relaciona o produto à sua raiz territorial, como forma de garantir a diferenciação produtiva de acordo com o regional, visto que, mesmo com os anseios globais em homogeneizar, não há territórios iguais.

É válido destacar que as ações estabelecidas pelas grandes empresas que atuam nos distintos territórios (dimensão global) e a reação de empresas com raízes territoriais (dimensão regional), não apenas configuram 0 estágio atual do desenvolvimento capitalista, como expõe uma forte contradição do mesmo sistema, isto é, padrões globais confrontados com características regionais. Baseando-se nestas perspectivas, verifica-se que os territórios fortalecem os aspectos particulares de sociedades regionais.

Esta realidade global, inicialmente introduzida nas indústrias transformadoras, se expandiu para diversos segmentos, entre eles o de alimentos e bebidas. Nas grandes corporações, as ações repetitivas são frequentes, a especialização de cada funcionário garante ao processo uma alta produtividade.

Assim como outros setores da economia, a enoalimentação também é influenciada pela relação dialética entre a dimensão global e a dimensão regional, não apenas na valorização e formação de uma identidade territorial, mas também no desenvolvimento dos indivíduos atuantes no contexto regional.

Verifica-se ainda, que o movimento de valorização da enogastronomia está fazendo também, com que esta "saia da cozinha e passe a ser objeto de estudo com a devida atenção à história, ao imaginário, ao simbólico, às representações e às diversas formas de sociabilidade ativa" (SANTOS, 2005).

O fenômeno passou a ser, centro de atenção de profissionais multidisciplinares, como cozinheiros, historiadores, antropólogos, sociólogos, geógrafos, enólogos e turismólogos, que passaram a refletir sobre o hábito de alimentar-se e as implicações culturais e sociais implícitas nesse ato, tanto na produção quanto no consumo dos alimentos.

Todavia, para compreender "saber fazer" como elemento de sustentação territorial, faz-se necessário discutir o entendimento sobre terroir, pois deste partem todos os pressupostos que irão se correlacionar a enogastronomia.

O conceito de terroir, de acordo com o dicionário Le Nouveau Petit Robert (1994), surgiu na França com o significado original de uma extensão limitada de terra, considerada sob o ponto de vista de suas aptidões agrícolas.

Terroir, na ampliação do conceito, desenvolvido por geógrafos franceses, é um conjunto de terras sob a ação de uma coletividade social, congregada por relações familiares e culturais, e por tradições de defesa comum e de solidariedade na exploração de seus produtos.

Para Tonietto (2007),

\begin{abstract}
A palavra terroir exprimi a interação entre o meio natural e os fatores humanos. E esse é um dos aspectos essenciais do terroir, de não abranger somente aspectos do meio natural (clima, solo, relevo), mas também, de forma simultânea, os fatores humanos da produção incluindo a escolha das variedades, aspectos agronômicos e aspectos de elaboração dos produtos. (TONNIETO, 2007, P.3)
\end{abstract}

Segundo o autor, nos dias atuais o termo terroir remete a uma conotação positiva em relação ao vinho, pois neste se percebe os requisitos necessários para a denominação de origem, isto é, a origem em si, a diferenciação e a originalidade do produto.

Para Valduga e Valduga (2007), este processo de produção regional está relacionado às características geográficas concretas (condições de clima, solo); as características das matérias primas agrícolas (as vinhas, o leite, o café, a carne); as técnicas de produção específicas na produção de produtos regionais, (o vinho, o queijo, os embutidos, o café), ao modo de vida e aos costumes da sociedade local. 
Neste sentido, o terroir pode ser definido como uma entidade territorial onde os valores patrimoniais são frutos de relações complexas e de longo tempo entre as características culturais, sociais, ecológicas e econômicas da região.

É importante salientar que este, se diferencia de espaço natural, pois para sua formação há necessidade de uma relação particular que relaciona a sociedade, suas práticas sociais e o habitat natural que gerou a paisagem da região.

O terroir não existe sem a presença do homem. Deve ser entendido como a equivalência entre o fator geográfico, o fator sócio econômico e o fator jurídico.

Então, pode-se afirmar que cada terroir é único e ainda que dois terroirs diferentes vão proporcionar dois produtos diferentes ao mercado.

Desta forma, é necessário ressaltar que os territórios estão se apropriando deste conceito para certificar e identificar seus produtos (indicações geográficas), a fim de possibilitar um melhor posicionamento, buscando desta forma, se diferenciar, valorizar e consequentemente, se desenvolver.

A enogastronomia, neste caso, contribui explicitamente para a valorização territorial, pois recupera e valoriza tradições territoriais, divulga os produtos e serviços, valoriza os produtores, identifica a produção, destaca o processo histórico social, expõe as particularidades do local e apresenta um modo de vida que se torna reconhecido por sociedades e mercados que atuam em escalas globais.

\section{A REGIÃO DO VALE DOS VINHEDOS}

As regiões vitivinícolas despertam o interesse de pesquisadores, estudantes, curiosos e visitantes de outras regiões por apresentarem especificidades regionais e territoriais que se expressam através de produtos ou atrativos particulares que possibilitam experiências do cotidiano regional.

Uma destas experiências é vivenciada na Região do Vale dos Vinhedos, no Estado do Rio
Grande do Sul, ao extremo sul do território Brasileiro que, a partir da chegada dos imigrantes (1875) no espaço localizado a nordeste do Estado, ocuparam a Encosta Superior do Planalto Meridional.

Esta área apresenta altitudes que variam de 200 a 742 metros, solo basáltico classificado como argilo-arenoso, clima subtropical com temperaturas médias entre $7^{\circ} \mathrm{C}$ e $29^{\circ} \mathrm{C}$ e chuvas anuais médias de $1.800 \mathrm{~mm}$ (APROVALE, 2014).

A região se localiza majoritariamente no espaço rural dos municípios de Bento Goncálves (60\%), Garibaldi (33\%) e Monte Belo do Sul (7\%), abrangendo uma área total de $81,123 \mathrm{~km}^{2}$, conforme dados da APROVALE, 2012. Como pode ser observado na Figura 1.

Figura 1: Localização da região do Vale dos Vinhedos no Estado do Rio Grande do Sul

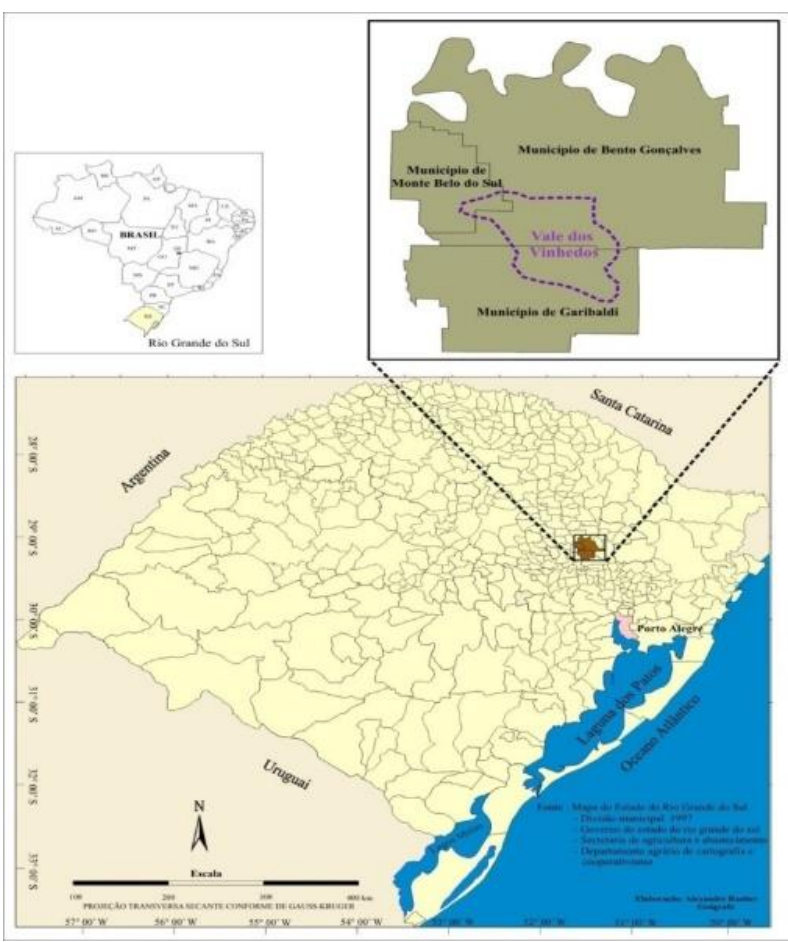

Fonte: Núcleo de Gestão Pública - Unisc (2012)

O território do Vale dos vinhedos se caracteriza por ter sua estrutura fundiária sustentada na agricultura familiar, constituída de pequenas propriedades rurais, com produção de uvas e derivados (sucos, doces, geleias, brandys e grapa), além de outros produtos agrícolas (hortifrutigranjeiros, milho e feijão) e pequenas criações de aves e suínos. 
Lamarche (1993) destaca que a agricultura familiar é uma forma de produção em que predomina a interação entre gestão e trabalho; são os agricultores familiares que dirigem 0 processo produtivo, dando ênfase à diversificação e utilizando o trabalho familiar, eventualmente complementado pelo trabalho assalariado.

O estilo da produção de alimentos de base familiar sugere o comprometimento do proprietário com a terra, assim como uma família cuida de sua casa. Conforme Pfetter (1989), não há separação da vida familiar do trabalho doméstico e das responsabilidades comuns a todos os membros com relação ao trabalho "no empreendimento".

A importância da produção familiar se reflete nas múltiplas funções da agricultura familiar inseridas na dinâmica sócio econômica dos territórios, e por isso deve ser valorizada, pois, garante a segurança alimentar, possibilita o acesso a diferentes tipos de alimentos e contribui, de forma efetiva, para o abastecimento de gêneros alimentícios no âmbito regional.

O Vale dos Vinhedos produz vinhos de qualidade; vinhos finos ${ }^{1}$, de mesa ${ }^{2}$ e espumantes ${ }^{3}$ e espumantes moscatel ${ }^{4}$, facilmente encontrados pelas inúmeras cantinas e vinhedos ao longo de toda região.

\footnotetext{
1 Vinho fino: vinho fino é o vinho de teor alcoólico de 8,6\% (oito inteiros e seis décimos por cento) a $14 \%$ (catorze por cento) em volume, elaborado mediante processos tecnológicos adequados que assegurem a otimização de suas características sensoriais e exclusivamente de variedades Vitis vinífera do grupo Nobres, a serem definidas em regulamento. (BRASIL, Lei № 10.970, 2004).

${ }^{2}$ Vinho de mesa: Vinho de mesa é o vinho com teor alcoólico de $8,6 \%$ (oito inteiros e seis décimos por cento) a $14 \%$ (catorze por cento) em volume, podendo conter até uma atmosfera de pressão a $20^{\circ} \mathrm{C}$ (vinte graus Célsius). (BRASIL, Lei $\mathrm{n}^{\circ}{ }^{10}$ 10.970, 2004).

3 Espumante: é o vinho cujo anidrido carbônico provém exclusivamente de uma segunda fermentação alcoólica do vinho em garrafas (método Champenoise/tradicional) ou em grandes recipientes (método Chaussepied/Charmad), com uma pressão mínima de 4 (quatro) atmosferas a $20^{\circ} \mathrm{C}$ (vinte graus Célsius) e com teor alcoólico de $10 \%$ (dez por cento) a $13 \%$ (treze por cento) em volume. (BRASIL, Lei no 10.970, 2004).

4 Espumante Moscatel: é o vinho cujo anidrido carbônico provém da fermentação em recipiente fechado, de mosto ou de mosto conservado de uva moscatel, com uma pressão mínima de 4 (quatro) atmosferas a $20^{\circ} \mathrm{C}$ (vinte graus Célsius), e com um teor alcoólico de 7\% (sete por cento) a 10\% (dez por cento) em volume, e no mínimo 20 (vinte) gramas de açúcar remanescente em seu volume. (BRASIL, Lei nº 10.970, 2004).
}

Dentre os vinhos finos, destacam-se as variedades tintas como a Cabernet Sauvignon, Cabernet Franc, Merlot, Tannat, Pinot noir, Gamay, Pinotage, Alicante, Bouschet, Ancelotta e Egiodola. Dentre as variedades brancas destacam-se a Chardonnay, Riesling Itálico, Sauvignon Blanc, Sémillon, Trebbiano, Pinot Blanc, Gewurztraminer, Flora, Prosecco, Moscatos e Malvasias.

Para os vinhos procedentes da vitis labrusca, vinhos de mesa, as principais variedades são a Bordô, a Izabel (tintas) e a Niágara (branca).

Com relação a produção de espumantes, a moscatel é a principal uva cultivada na região e que melhor representa a qualidade dos espumantes fabricados no Vale dos Vinhedos. O quadro apresenta as principais variedades e características das uvas cultivadas no Vale dos Vinhedos, bem como os tipos de vinhos resultantes delas.

A vinicultura e a vitivinicultura do Vale são as principais características que se apresentam no território, e seu cultivo e produção, datam no período inicial de imigração no Rio Grande do Sul.

Conforme Valduga e Valduga (2007), a escolha do vinho como símbolo territorial e principal produto do Vale dos Vinhedos não é aleatória, pois, ele representa a cultura do imigrante italiano e economicamente está ligada a "monocultura familiar" da uva.

Outra característica marcante do vale dos vinhedos é a gastronomia colonial italiana, popularmente conhecida como "comida de gringo" que se encontra nos restaurantes ao longo do território.

No Vale dos Vinhedos não ocorreu uma mera reprodução da cultura gastronômica italiana, surgiu, na realidade, uma cultura peculiar, de características próprias que pode ser denominada de colonial. Ela reuniu e fundiu alguns costumes alimentares trazidos pelos imigrantes, metamorfoseou outros e incorporou alimentos já existentes no Rio Grande do Sul.

Pratos estes que foram se moldando ao longo dos tempos e adicionando a gastronomia italiana, os ingredientes aqui encontrados, recriando desta 
maneira, uma gastronomia original, peculiar e específica da região.

A incorporação do chimarrão aos hábitos dos imigrantes, além do vinho, auxiliou na construção desta gastronomia colonial.

Isso acontece porque a existência de fronteiras entre diferentes grupos étnicos não está diretamente vinculada com a manutenção de suas culturas, mas sim com o modo de vida e o saber fazer local destes, que a priori, os identifica através de uma relação de pertencimento impregnada nas relações sociais e culturais destes diferentes grupos étnicos.

Aspectos como os câmbios territoriais (migrações), a busca pela essência da alimentação autóctone, a utilização de diferentes ingredientes, sabores e aromas, aliados a modos de preparo originais contribuem sim, para o fortalecimento da identidade da cozinha colonial, ao mesmo tempo que define e constitui esta, como autêntica, genuína e peculiar.

A cozinha colonial conserva traços culturais, modos de preparo tradicionais e serviços de mesa originais que "andam" na contramão dos processos de padronização dos serviços de alimentação mundo a fora. E é justamente esse processo dialético, de passado versus presente, clássico versus moderno e de tradição versus inovação que a fortalece e a torna tão encantadora e atrativa, e desperta desta forma, a curiosidade dos visitantes.

As somas destes fatores constituem a diferenciação e a singularidade territorial, aspectos fundamentais para a valorização e sobrevivência dos modos e costumes que identificam sociedades ou grupos coloniais.

É importante ressaltar que outras particularidades coloniais também estão impregnadas em diversos elementos que caracterizam a gastronomia do Vale, e atraem visitantes à região, como: a) a decoração, atendimento e serviço de mesa dos restaurantes; b) a comercialização de produtos coloniais e; c) a divulgação de produtos ou pratos locais em festas e eventos.

A pluriatividade também caracteriza a região do Vale dos Vinhedos, pois além do trabalho agrícola e do trabalho nas cantinas, os trabalhadores atuam na prestação dos serviços de turismo, como o enoturismo e a hotelaria.

Segundo a Aprovale (2014) o Vale dos Vinhedos também é composto por comunidades ${ }^{5}$, que trazem denominações das capelas construídas pelos primeiros colonizadores. Essa afirmação salienta para outra característica importante encontrada na região, a religiosidade do povo. Relatos afirmam que, em cada comunidade que se formava na região, a primeira construção era sempre uma capela ou igreja.

Outra característica marcante do Vale dos Vinhedos é o empreendedorismo local. Conforme dados apresentados pelo Sindicato de Hotéis, Bares e Restaurantes da Região Uva e Vinho (2014), existem 15 restaurantes, 5 vinícolas que oferecem serviços de alimentação mediante reserva e 27 vinícolas registradas, divididas entre pequeno porte, médio porte e grande porte ${ }^{6}$.

Além destes, é possível encontrar no Vale dos Vinhedos, lojas de artesanato, de móveis rústicos e artigos em couro, lojas de aromatizantes e essências de vinho, pousadas, pontos de vendas de caixas de uva, casas coloniais com venda de alimentos típicos, produção de cogumelos, entre outros.

Por fim, cabe destacar que características como essas foram se moldando no tempo, através da apropriação do território pelo imigrante, e que, a partir de suas necessidades, sonhos ou aspirações, transformou o espaço e contribuiu para o processo de formação do terroir do Vale dos Vinhedos.

\section{O SABER FAZER ENOGASTRONÔMICO DO VALE DOS VINHEDOS}

Para analisar o saber fazer enogastronômico do território do Vale dos Vinhedos foi necessário compreender a dinâmica da realidade (materialismo histórico), através de uma série de aspectos que se

\footnotetext{
${ }^{5}$ Comunidades do Vale dos Vinhedos: Linha Garibaldina, Linha Ceará da Graciema, Linha 8 da Graciema, Linha 15 da Graciema, Linha Santa Lúcia, Linha 40 da Graciema, Linha 40 da Leopoldina, Capela das Almas da Linha Leopoldina, Capela das Neves da Linha 6 da Leopoldina e Linha Zemith

${ }^{6}$ Porte: adotou-se a quantidade de litros de vinho produzidos e envasados pelas vinícolas para se definir o porte, conforme fonte APROVALE (2014).
} 
apresentaram ao longo das análises das entrevistas já mencionadas. Dentre os aspectos necessários para a compreensão do saber fazer enogastronomico do território, destacam-se:

a) Cultura enogastronômica - percebe-se que, além do conhecimento sobre o processo histórico de formação cultural do vale dos vinhedos, há respeito, admiração e valorização pela figura e representação cultural do imigrante italiano.

A valorização do imigrante e sua representação social, no sentido de valorização deste, como homem da terra, agricultor, que sobrevive da produção no meio rural foram repassadas de geração para geração.

Isto desperta o sentimento de pertencimento ao território, independentemente da situação financeira em que se encontra e, neste sentido verifica-se que valorização da enogastronomia é algo impregnado e está enraizada no modo de ser do indivíduo nativo do Vale dos Vinhedos.

Desta forma, pode-se afirmar que a enogastronomia, quando perpassa por uma simbologia relacionada aos costumes sociais, passa a ser valorizada enquanto cultura e desperta nas pessoas a curiosidade em conhecê-la e portanto, além de ser uma necessidade fisiológica, se tem a possibilidade de consumir heranças culturais da imigração italiana no RS.

b) Uva e vinho: a tradição vitivinícola da região do vale dos vinhedos se inicia junto ao seu processo de formação e percebe-se através das análises realizadas que os entrevistados sabem da importância do "produto" vinho e de seus subprodutos para o território. Pois a partir dele, há geração de emprego e renda, há crescimento econômico na região e possibilidades para novos negócios, há desenvolvimento do turismo (enoturismo) e há credibilidade dos produtos da região, através das indicações geográficas.

Os entrevistados conhecem a gama de benefícios que a enogastronomia pode proporcionar e proporciona ao Vale dos Vinhedos, como a entrada de divisas, a criação de subprodutos oriundos da uva, a geração da atividade econômica secundária e o aumento do lucro por garrafa de vinho vendida no varejo. Os próprios agricultores reconhecem que a atividade possibilita a descoberta de toda região.

c) Identidade territorial - A identidade territorial se expressa, dentre outros, através da enoalimentação. Identidade esta, construída a partir da interiorização de uma tradição, onde afinidades foram estabelecidas e transmitidas a pessoas que vivenciam o sentimento de pertencer a determinados grupos sociais (RITTER, 2011).

É sabido que a enogastronomia do Vale, é sem dúvida alguma, um meio de identificação de sua sociedade, pois através dela se torna possível conhecer a história, os hábitos, os costumes, as crenças e os valores de sua sociedade regional. Neste sentido, Schlüter afirma que:

A identidade também é expressa pelas pessoas
através da gastronomia, que reflete suas
preferências e aversões, identificações e
discriminações, e, quando imigram, a levam
consigo, reforçando seu sentido de
pertencimento ao lugar de origem. Dessa forma
vai-se criando uma cozinha de caráter étnico,
explorada com muita frequência no turismo para
ressaltar as características de uma cultura em
particular. (SCHLÜTER, 2003, p. 32).

A dimensão social e cultural da enogastronomia, em incorporar processos alimentares que fomentem o desenvolvimento das sociedades, contribui na formação da identidade social das sociedades, que trazem consigo a expressão de seus estilos de vida. Através da enogastronomia, se expressam marcas do passado, da história, da sociedade e da região a qual se pertence.

Neste sentido, pode-se destacar que os hábitos enogastronômicos da sociedade estão além das sensações relacionadas a cores e sabores dos alimentos, eles diferenciam valores sociais e culturais como a religião, a etnia e a história social.

É válido salientar que a identidade territorial se mostra através de diferentes percepções, como o caso do sentimento de pertencimento e da valorização das tradições do Vale dos Vinhedos. 


\section{CONSIDERAÇÕES FINAIS}

A perspectiva da enogastronomia aqui estudada não se limitou somente a análise do saber fazer do território do Vale dos Vinhedos, mas também buscou conhecer a região através do estudo de caso.

No desenvolvimento do trabalho foi possível atingir todos os objetivos pré-determinados, além de responder a temática central que norteou este artigo, o saber fazer enogastronômico do território do Vale dos Vinhedos.

Conforme Silva (2015), as particularidades regionais, no processo de identificação do saber fazer, estão ligadas à cultura enogastronômica da região, representadas através da figura do imigrante e suas características; ao cultivo e a produção da uva, do vinho e as relações existentes com a agricultura de base familiar e a valorização da identidade territorial existente na região a partir dos traços culturais herdados pela sociedade.

Neste sentido, percebe-se que a relação dos imigrantes com o vinho está ligada ao processo histórico da cultura italiana e, portanto, anterior a própria imigração italiana para a colonização no Rio Grande do Sul.

Os produtos oriundos do Vale dos VInhedos, resultantes de um longo trabalho de busca da qualidade da produção são importantes para a construção do saber fazer, pois impulsionam a região economicamente, transmitem credibilidade vitivinícola ao Vale dos Vinhedos e fortalecem o sentimento de pertencimento regional.

$\begin{array}{ccccc}\text { Neste } & \text { sentido, } & \text { verifica-se } & \text { que } & \text { a } \\ \text { enogastronomia } & \text { também } & \text { contribui } & \text { para } & 0\end{array}$ fortalecimento do saber fazer da região do Vale dos Vinhedos tendo em vista que além dos vinhos e sua gastronomia típica colonial italiana, o território, os atores sociais (agricultores familiares, empresários, assalariados) e o modelo produtivo da região, são objetos de interesse a serem conhecidos, estudados e observados por pesquisadores, estudantes, visitantes e turistas, que se interessam pela localidade.

A enogastronomia no Vale dos Vinhedos integra o fortalecimento de um território único e peculiar, pois mantem tradições, costumes e modos de vida oriundos de um período colonial que se confunde com o processo de ocupação territorial desde o século XIX e que por si só, cria laços culturais regionais e resgata no imaginário regional, um sentimento de pertencimento que reconhece a cultura enogastronômica local como original.

A revitalização dos traços culturais e a redefinição do território estão acumuladas na memória coletiva dos indivíduos que se sentem pertencentes ao lugar.

O fortalecimento dos traços e das características sócio culturais da enogastronomia do Vale criou hábitos e práticas que contribuíram para a criação de um imaginário coletivo, que permitiu aos moradores da região (re) afirmarem a sua noção de pertencimento à região.

A enogastronomia colonial italiana do Vale dos Vinhedos, representada nos restaurantes, cantinas e nas casas de comercialização de alimentos típicos atrai turistas e visitantes, pois seu modo de preparo, seus ingredientes, sua apresentação e seus seu hibridismo (mescla da alimentação do norte da Itália com a cozinha gaúcha) a torna tão particular que desperta a curiosidade das pessoas.

A perspectiva da enogastronomia aqui discutida não se limitou a considera-la sob o aspecto da harmonização entre vinhos e alimentos ou sob empresas de alimentos e bebidas (restaurantes e vinícolas). Do contrário, buscou-se apresentar uma nova percepção do que é enogastronomia, isto é, um tema amplo, complexo, com contradições e que merece ser discutido com atenção, pois seu significado, está diretamente ligado ao território, a produção agrícola de base familiar e as empresas enogastronômicas.

Neste sentido, verifica-se que este artigo acrescentou novos elementos aos estudos relacionados a enogastronomia, pois discutiu-se questões relacionadas a complexidade do tema, como o saber fazer enogastronômico.

Dentre as contribuições empíricas, acredita-se que a pesquisa oferece possibilidades de leituras 
para outras áreas, como enologia, economia, história, gestão pública e empreendedorismo.

Por fim, pode-se afirmar que o estudo contribui para o desenvolvimento regional. Todavia, este não se encerra em si e, longe de qualquer pretensão de esgotamento sobre o tema ou construção absoluta do conhecimento, abre possibilidades para a continuidade da busca pelo estado da arte no que tange a identidade territorial e consequentemente 0 desenvolvimento de regiões.

\section{Referências}

ABRAMOVAY, R. Bases para a Formulação da Política Brasileira de Desenvolvimento rural: Agricultura Familiar e Desenvolvimento Territorial. Brasília: IPEA, 1998.

ANDRADE, Manuel Correia. A Questão do território no Brasil. São Paulo: Hucitec; Recife, 1995.

ANDRÉ, Marli Eliza Dalmazo Afonso de. Estudo de Caso em Pesquisa e avaliação educacional. Brasília: Liber Livro Editora, 2005.

ASSOCIAÇÃO DOS PRODUTORES DE VINHOS FINOS DO VALE DOS VINHEDOS - Aprovale. Disponível em: <http://www.aprovale.com.br>. Acesso em: ago. 2012

ASSOCIAÇÃO DOS PRODUTORES DE VINHOS FINOS DO VALE DOS VINHEDOS - Aprovale. Disponível em: <http://www.aprovale.com.br>. Acesso em: ago. 2014.

BRASIL. Lei no 10.970, de 12 de novembro de 2004: a produção, circulação e comercialização do vinho e derivados da uva e do vinho. Disponível em: <http://www.receita.fazenda.gov.br/legislacao/Leis/20 04/lei10970.htm>. Acesso em: dez. 2014.

BRASIL. lei no 7.678, de 8 de novembro de 1988: a produção, circulação e comercialização do vinho e derivados da uva e do vinho. Disponível em: <http://www.receita.fazenda.gov.br/legislacao/Leis/20 04/lei10970.htm>. Acesso em dez. 2014.

BRASIL. Lei no 9.279, de 14 de maio de 1996 - Lei da Propriedade Industrial. Brasília, Ministério do Desenvolvimento, Indústria e Comércio Exterior, 1996.

LAMARCHE, Hugues (coord.). A agricultura familiar: comparação internacional. V. I: Uma realidade multiforme. Campinas: Editora da Unicamp, 1993.

LE NOUVEAU PETIT ROBERT, Dictionnaire de la Langue Française. Paris: Le Robert 1994.

MARTINS, Lígia Márcia. As aparências enganam: divergências entre o materialismo histório dialético e as abordagens qualitativas de pesquisa. Reunião Anual da Anped, 2006. Disponível em: $<$ http://stoa.usp.br/mpp5004/files/-

1/18605/As+apar\%C3\%AAncias+enganam+diivergencias+entre+o+mhd+e+as+abordagens+qualit ativas.pdf>. Acesso em: jan. 2014.

MARX, Karl. Para a Crítica da Economia Política: Salário, Preço e Lucro. O Rendimento e Suas Fontes: traduções de Edgard Malagodi. São Paulo: Abril Cultural, 1982.

; JEZIORNY, Daniel Lemos. Vinho e território: a experiência do Vale dos Vinhedos. Campinas: Alínea, 2011.

RAFFESTIN, Claude. Por uma geografia do poder. São Paulo: Ática, 1993.

RITTER, Carlos. Reflexões Epistemológicas Sobre os "Territórios se Identidade". Revista Geografar. V.6, N.1. Curitiba, 2011. Disponível em: <http://ojs.c3sl.ufpr.br/ojs/index.php/geografar/article/v iewFile/21805/14197>. Acesso em: abr. 2015.

SANTOS, Milton. Por Uma Outra Globalização: do Pensamento Único à Consciência Universal. Rio de Janeiro. Record: 2000.

SCHLÜTER, Regina G. Gastronomia e Turismo. Aleph. São Paulo, 2003

SILVA, Roberto do Nascimento e. A enogastronomia do processo de formação de identidade territorial do Vale dos Vinhedos. Tese de Doutorado. Universidade de Santa Cruz do Sul. Santa Cruz do Sul, 2015.

TONIETTO, Jorge. Afinal, o que é Terroir? Bon Vivant, v. 8, n. 98. Flores da Cunha, 2007.

TRIVIÑOS, A. N. S. Introdução à Pesquisa em Ciências Sociais: A Pesquisa Qualitativa em Educação. São Paulo, Atlas, 1987.

VALDUGA, Gustavo. VALDUGA, Vander. Região, Vinho $E$ Identidade: Uma Visão Sobre o Vale dos Vinhedos. Artigo. Bento Gonçalves, 2007. 